\title{
AS DITADURAS NO CONE SUL: UM PASSADO PRESENTE, UM DEBATE URGENTE!
}

\author{
Tatyana de Amaral Maia \\ Paulo Giovani Antonino Nunes ${ }^{2}$
}

\begin{abstract}
"Um povo sem História não é gente, não pode ser gente, não tem como ser gente." A frase, pronunciada por uma lavradora analfabeta e transcrita em nota da ANPUH-DF ao tratar da destruição recente do Museu Nacional ${ }^{3}$, sintetiza a função social e o compromisso ético da História com as gerações atuais e futuras. A História, fruto da construção epistemológica do conhecimento na modernidade, encontra-se hoje envolvida numa trincheira em favor da democracia, da ciência, dos direitos humanos, do qual é caudatária. Dos diversos temas e objetos que são de interesse dos historiadores, aqueles dedicados à História recente, sobretudo, aos regimes ditatoriais do século XX vêm sendo alvo de negação considerados frutos do anti-intelectualismo emergente e de uma política do ódio que desconsidera o "Outro", suas diferenças, direitos e pluralidades. Neste sentido, este número temático assumiu o compromisso de trazer a público, a partir dos cânones epistemológicos da pesquisa histórica, artigos dedicados às ditaduras no Cone Sul, considerando seus aspectos transnacionais $e$ as especificidades das experiências nacionais. A pluralidade de temas, recortes, fundamentação teórica, fontes e metodologias reforçam os princípios da multicausalidade na construção da narrativa histórica, cujo rigor não está na exclusão de abordagens, mas na valorização de diferentes referenciais teórico-metodológicos, no domínio da historiografia e no uso de fontes.

Em nota recente, publicada em 22 de outubro de 2018, a Associação Nacional de História ANPUH - manifestou-se publicamente através de seu site, sobre a preocupação com o silenciamento da História da ditadura brasileira. Na nota, reforçou a importância do relatório final da Comissão Nacional da Verdade, resultado da ação do Estado em busca da "verdade", ou seja, da investigação acerca das violações de Direitos Humanos promovidas pelo Estado ditatorial brasileiro. Dois dias depois, o site da ANPUH publicava a nota do Grupo de Trabalho Ensino de História e Educação sobre a importância da defesa da Democracia, da Igualdade, da Liberdade e da Diferença, resultado da preocupação do GT com a desvalorização desses ideais modernos no cenário político nacional. ${ }^{4}$ Tais notas e manifestos somam-se à ação arraigada da Associação de manter os valores democráticos e a liberdade de ensino e pesquisa, dentro da proposta de um Estado de Direito, laico, baseado no respeito à pluralidade de ideias, posicionamentos políticos e opiniões, e funcionam como estratégias de resistência ao avanço do autoritarismo e do anti-intelectualismo no campo político. ${ }^{5}$

Nos últimos anos, observamos a emergência de movimentos e governos de direita no mundo Ocidental cujo sucesso eleitoral está associado a uma crítica voraz aos valores mais caros da modernidade, dentre eles, a democracia, a igualdade, a liberdade, a ciência, os direitos fundamentais à vida. O avanço desses governos na Europa e nas Américas tem suscitado inúmeros debates no mundo
\end{abstract}

\footnotetext{
${ }^{1}$ Doutora em História pela UERJ, com pós-doutorado na UFF (2012) e na Universidade do Porto (2014). É professora adjunta do Programa de Pós-Graduação em História e da graduação em História da PUCRS. e-mail tatyana.maia@pucrs.br.

${ }^{2}$ Doutor em História do Brasil pela Universidade Federal de Pernambuco (UFPE). Realizou estágio pós-doutoral junto ao Programa de Pós-Graduação em História da Universidade Federal de Minas Gerais (UFMG). Professor Associado do Programa de Pós-Graduação em História e da graduação em História da Universidade Federal da Paraíba (UFPB), Campus I, João Pessoa.e-mail - pauloantoninonunes@hotmail.com.

${ }^{3}$ Nota da ANPUH-DF. Um povo sem História não é gente, não pode ser gente, não tem como ser gente. https:/anpuh.org.br/index.php/2015-01-20-00-01-55/noticias2/noticias-destaque/item/4860-nota-da-anpuh-df-um-povo-semhistoria-nao-e-gente-nao-pode-ser-gente-nao-tem-como-ser-gente. Acessado em: 29/11/2018.

${ }^{4}$ Associação Nacional de História. Nota da ANPUH sobre a tentativa de apagamento. https://anpuh.org.br/index.php/201501-20-00-01-55/noticias2/noticias-destaque/item/4930-nota-da-anpuh-brasil-sobre-a-tentativa-de-apagamento-da-historia-daditadura-militar-no-brasil acessado em: 29/11/2018; GT Ensino de História e Educação, ANPUH. Manifestação pública em defesa da democracia. https:/anpuh.org.br/index.php/2015-01-20-00-01-55/noticias2/noticias-destaque/item/4937manifestacao-publica-em-defesa-da-democracia. Acesso em: 29/11/2018.

${ }^{5}$ No site da associação é possível ter acesso a diversas notas e manifestos publicados em defesa da democracia contra os discursos que incitam a censura, o ódio e a violência no cenário político brasileiro atual. Ver: https://anpuh.org.br/ Acesso em: $30 / 11 / 2018$.
} 
intelectual. $\mathrm{O}$ apoio de parcelas heterogêneas da população a esses projetos políticos conservadores nasce da descrença na capacidade dos modelos políticos baseados na social-democracia, que prevaleceram no Ocidente no pós-guerra, de responderem aos desafios postos para as sociedades ocidentais no tempo presente. A crise econômica do capitalismo mundial, a perda da capacidade de consumo das famílias de classe média, o desemprego, o crescimento dos índices de violência nas grandes cidades, sobretudo, na América Latina, contribuem para agravar o quadro. Por outro lado, a força da ação política dos grupos minoritários, que pressionam os governos eleitos em torno de suas causas legítimas, reforçou a perspectiva dos grupos conservadores de que o mundo estaria à beira da desordem. Essa sensação de descontrole tem sido abordada pelos intelectuais desde os anos de 1990 como característica do mundo Ocidental e é considerado parte da crise provocada pelo presentismo. ${ }^{6}$ No entanto, para certos grupos a solução para suas inquietudes e inseguranças passa perigosamente pelo apoio a ideologias de extrema-direita que estão dispostas a desconsiderar o avanço produzido pelo pensamento moderno, sobretudo, a democracia, a liberdade de expressão e a justiça social, em seus projetos de poder.

No atual quadro de negação da contribuição dos valores modernos para a vida coletiva, as diversas áreas da ciência no Brasil têm sido alvo de ataques dos grupos mais conservadores, sendo minorada a capacidade da História de elaboração de um conhecimento capaz de produzir assertivas válidas $e$ controlar a subjetividade presente em qualquer narrativa, incluindo a científica. ${ }^{7}$

Neste sentido, confunde-se, através das batalhas de memória, o lugar da História na produção de narrativas sobre o passado. Mas, por que o passado ordenado, criticamente investigado e qualificado pela ação dos historiadores através da pesquisa histórica assusta? Se o passado é o tempo mais estável dos três tempos, não deveríamos ter receio do futuro, tempo sobre o qual temos apenas expectativas? Afinal, a incerteza não estaria justamente no tempo futuro, marcado pelas contingências que ultrapassam nossos desejos individuais e teimam em nos levar para caminhos inicialmente nãoplanejados?

No entanto, é o passado que se tornou alvo daqueles grupos conservadores que reconhecem a força da História no tempo presente e nas escolhas sobre o futuro. Mas, como os historiadores trabalham e como produzem o conhecimento sobre o passado?

A narrativa histórica é um tipo de narrativa específica, elaborada a partir da ação dos historiadores que selecionam, reúnem e ordenam as experiências vividas, propondo uma narrativa que as torne inteligíveis. Tal elaboração, no entanto, não é fruto do voluntarismo dos historiadores no exercício da profissão. A epistemologia da história ocupa-se fundamentalmente em definir como a História pode produzir uma narrativa de caráter objetivo e aceita pelos pares como válida. Primeiro, a despeito das diferenças entre as escolas históricas, as fontes foram e são consideradas fundamentais na busca pela validade das assertivas produzidas. Segundo, há um diálogo exaustivo com os pares, que ocorre através do conhecimento prévio já produzido acerca de determinado tema. Por fim, a adoção de um aparato conceitual. Esses três princípios atuam na produção da narrativa histórica. A partir deles, a subjetividade da narrativa, intrínseca a qualquer área do conhecimento, encontra-se aceitavelmente controlada. ${ }^{8}$ Ao contrário dos movimentos negacionistas, que abusam da memória e não precisam seguir um método rigoroso na elaboração de suas narrativas, no caso da História, a narrativa necessariamente precisa explicitar suas opções metodológicas e teóricas, o domínio da historiografia pré-existente e as fontes que sustentam as hipóteses elaboradas.

Os historiadores sabem, desde meados do século $\mathrm{XX}$, que os três tempos, o vivido, o atual e as expectativas do porvir se entrecruzam, sempre a partir da tensão, no presente, entre aquilo que já foi $e$ o que esperamos viver. ${ }^{9}$ É por isso que acionamos do passado apenas o que consideramos necessário para dar sentido à vida presente. A História constrói sentidos para o vivido, retirando do caos as experiências coletivas, dotando-lhes de um significado capaz de ordenar a vida em sociedade. Assim, o passado nos interessa como ferramenta imprescindível na compreensão do que somos e, sobretudo,

\footnotetext{
${ }^{6}$ GIDDENS, Antonhy. Mundo em descontrole. O que a globalização está fazendo de nós. Rio de Janeiro: Record, 1999.

${ }^{7}$ Projetos como Escola Sem Partido, narrativas que defendem o combate a uma suposta "ideologia de gênero", grupos organizados como Movimento Brasil Livre são exemplos dos movimentos de extrema-direita que tem espaço no cenário político brasileiro atual.

${ }^{8}$ Para uma discussão mais ampla sobre o tema, ver REIS, José Carlos. O desafio historiográfico. Rio de Janeiro: FGV, 2010.

${ }^{9}$ KOSELLECK, Reinhart. Futuro passado: contribuição à semântica dos tempos históricos. Rio de Janeiro: Contraponto/Ed. PUCRio, 2006.
} 
do que desejamos vir a ser. É por este motivo também que em períodos de crise dos valores democráticos, controlar as narrativas sobre passado torna-se fundamental para os grupos autoritários. O controle sobre tais narrativas pode facilitar a construção de representações do mundo social que legitimam seus projetos de futuro, silenciado a existência de projetos concorrentes e alternativos. Se tais projetos autoritários forem identificados com supostas tradições coletivas e esvaziarem as contradições e dissensos existentes numa sociedade plural, melhor ainda para legitimar as ações orquestradas por tais grupos.

A abertura dos arquivos sobre os períodos discricionários, a investigação das violações dos Direitos Humanos nas ditaduras do Cone Sul, a construção de lugares de memória acerca dos nossos passados dolorosos, a constatação de que grupos minoritários são alvos constante de opressão pelos donos do poder político e econômico, tornam a História um conhecimento indispensável na forma como compreendemos a nossa trajetória coletiva. A História é capaz de contribuir significativamente para ampliar as nossas experiências individuais, auxiliando na nossa tomada de posição sobre os projetos políticos e econômicos em disputa que concorrem entre si pelo ordenamento da vida coletiva. Ou seja, os historiadores contribuem na formação da consciência histórica.

A maneira como lidamos com o passado diz muito acerca do presente em que vivemos e dos nossos projetos de futuro. No caso dos passados dolorosos, como as ditaduras do Cone Sul, as formas como narrarmos e compreendemos esse passado é um importante indicativo sobre a nossa capacidade de romper com os legados do período ditatorial e de fazer valer as bases do Estado de Direito que construímos. Quando o Estado de Direito ainda traz consigo as feridas abertas pelos regimes ditatoriais e opta pela promoção do esquecimento, então, não é possível falarmos em reconciliação nacional. A reconciliação nacional não se faz através do esquecimento ou do silenciamento, que cobre com o manto da impunidade os responsáveis pelo arbítrio. ${ }^{10}$ Neste sentido, o dossiê aqui proposto cumpre o papel acadêmico de abrir novos espaços de reflexão e diálogo, contribuindo para a ampliação da consciência histórica ao compartilhar as experiências vividas sob o crivo da História.

Nos últimos quarenta anos, pesquisadores dedicados às ditaduras no Cone Sul têm buscado compreender as experiências nacionais singulares, considerando que cada regime autoritário respondeu a projetos específicos, bem como têm apresentado possibilidades de comparação de tais modelos autoritários, desde o golpe até a redemocratização. Pesquisar as ditaduras no século XX é uma opção intelectual fundamental para fortalecer a democracia. Aliás, para nós, foi uma grata surpresa o número de artigos submetidos por doutorandos para este dossiê. Ao lado de historiadores experientes e consagrados, que trazem análises sólidas e de grande lastro interpretativo, acreditamos que as pesquisas dos jovens historiadores também oxigenam os trabalhos dedicados ao tema, contribuindo enormemente para a historiografia.

Os golpes e as ditaduras do Cone Sul têm sido objeto recorrente da historiografia latino-americana. Diversos sociólogos, historiadores e cientistas políticos produziram importantes análises sobre os múltiplos fatores que levaram ao fim da experiência democrática nesses países, as estruturas ditatoriais e os legados para as democracias na Argentina, no Brasil, no Chile, no Uruguai e no Paraguai. A partir de investigações sobre as especificidades nacionais, ou ainda de análises comparativas, é possível levantarmos algumas características que atravessam tais experiências ditatoriais. Todas foram vividas dentro do ambiente de Guerra Fria, marcada por forte anticomunismo e pela ação dos Estados Unidos na desestabilização e derrubada dos regimes democráticos. A Doutrina de Segurança Nacional, ainda que apropriada e modificada para atender às especificidades de cada realidade nacional, foi um elemento fundamental na construção do Terrorismo de Estado. A repressão sistemática e a instauração de um aparato repressivo ultrapassaram as fronteiras nacionais, já amplamente conhecidas através de pesquisas dedicadas à Operação Condor. A invenção de um "inimigo interno" foi utilizada para a promoção da repressão, da censura, da cultura do medo e favoreceu a implementação do processo de modernização autoritária e conservadora nos moldes do capitalismo tardio. ${ }^{11}$ Ao lado da organização

\footnotetext{
${ }^{10}$ MEZAROBBA, Glenda. Do que se fala, quando se diz Justiça de Transição? Revista Brasileira de Informação Bibliográfica em Ciências Sociais. São Paulo: ANPOCS, v.67, 2010, p. 111-122.

${ }^{11}$ Sobre a Doutrina de Segurança Nacional, ver COMBLIN, Joseph. Ideologia de Segurança Nacional. Rio de Janeiro: Civilização Brasileira, 1978. Sobre o "Terrorismo de Estado", ver PADRÓS, Enrique Serra. América Latina: Ditaduras, Segurança Nacional e Terror de Estado. Revista História \& Luta de Classes, v. 4, p. 43-49, 2007. Sobre a participação da sociedade civil, silêncios, apoios e consentimento, ver ROLLEMBERG, Denise e QUADRAT, Samantha Viz. Apresentação. In:
} 
de diversas formas de resistência, também é possível verificar a existência de grupos civis que apoiaram, colaboraram e se beneficiaram diretamente com as ditaduras. Assim, ao lado dos militares, segmentos da sociedade civil apoiaram os golpes de Estado e atuaram diretamente na construção $e$ na legitimação dos regimes ditatoriais do Cone Sul. A violação dos direitos humanos e o uso ilegítimo da violência de Estado, promovendo a "guerra suja" foi a face mais dolorosa dessas ditaduras, mas é importante lembrar também dos altos custos sociais pagos pela adoção de uma modernização excludente, que atingiu os segmentos mais pobres e vulneráveis da população.

A redemocratização nesses países ocorreu de formas distintas: por ruptura (como no caso argentino) ou por negociação sob controle dos militares (no caso brasileiro), incidindo diretamente sobre as ações empreendidas dentro do campo da Justiça de Transição. Ainda durante o ocaso dos regimes ditatoriais começam a surgir testemunhos e ações de vítimas e familiares de mortos e desaparecidos que exigem verdade, memória e justiça. Esse tripé marca a chamada Justiça de Transição no Cone Sul. Cada país passou a promover ações na tentativa de atender, em graus diferentes, uma reparação possível e, em alguns deles, realizou-se o julgamento dos agentes responsáveis pelas graves violações de direitos humanos. As ações promovidas pelos Estados pós-redemocratização responderam diretamente ao processo de redemocratização vivido. No caso brasileiro, trata-se de um processo que foi controlado pela cúpula militar e, portanto, marcado pela adoção de medidas que consagraram a impunidade, cujo símbolo máximo foi a Lei da Anistia de $1979 .{ }^{12}$

No que concerne à questão da Justiça de Transição, em alguns países do Cone Sul foram instaladas, em momentos diferentes, comissões da verdade. Na Argentina e no Chile, logo após o final das respectivas ditaduras, no Brasil, 26 anos após o fim da mesma. ${ }^{13}$

Na Argentina, logo após o término da ditadura militar, em 1983, o presidente constitucional Raúl Alfonsin instituiu por decreto presidencial a Comisión Nacional sobre la Desaparicion de Personas, que buscou investigar o caso dos militantes políticos desaparecidos, mas deixou de fora das investigações o caso emblemático das crianças, filhas de pessoas de esquerda, que foram separadas de seus familiares e entregues a simpatizantes do regime militar. Segundo Stampa e Rodrigues, mesmo assim,

(...) seu relatório final contribuiu como elemento informativo e probatório para procedimentos judiciais que levaram, posteriormente, à prisão de alguns líderes do regime militar. Sua limitação à questão dos desaparecidos, contudo, foi duramente criticada, e o problema de justiça transicional ainda se faz presente atualmente no país. ${ }^{14}$

No Chile, a comissão da verdade foi estabelecida com o fim da ditadura liderada pelo general Augusto Pinochet, em 1990, mas apesar de já vigorar a democracia, com um governo eleito democraticamente, o referido general, na condição de comandante do Exército, ainda detinha muitos poderes e pressionou tanto o governo de Patricio Aylvin como a comissão. Dessa forma, o relatório da comissão permaneceu secreto por um longo período e seu mandato não investigou os casos de tortura que não tiveram como resultado a morte das vítimas. Mas de acordo com Stampa e Rodrigues, "De qualquer forma, ao final dos trabalhos da comissão, o então presidente Patricio Aylvin (1990-1994) desculpou-se publicamente pelas violações perpetradas durante a ditadura militar". ${ }^{15}$

Nos anos 2000, numa conjuntura marcada por governo progressistas nos países do Cone Sul, novas iniciativas foram tomadas visando alterar a cultura da impunidade. No Chile, o então presidente Ricardo Lagos criou, em 2003, uma nova comissão da verdade, que ficou conhecida com "Comissão Valech", para ampliar as investigações da comissão anterior, e na Argentina, a Corte Suprema anulou

A construção social dos regimes autoritários: legitimidade, consenso e consentimento no século XX. Rio de Janeiro: Civilização Brasileira, 2010, 3v.

${ }^{12}$ BRITO, Alexandra Barahoma; ENRIQUEZ-GONZALEZ, Carmen; FERNANDEZ, Paloma Aguilar. Política da memória: verdade e justiça na transição para a Democracia. Lisboa: Universidade de Lisboa, 2004.

${ }^{13}$ No âmbito do Cone Sul também foi criada em 1985 a Comissión Investigadora sobre la Situación de Personas Desaparecidas y hechos que la motivaron, no Uruguai, com objetivo de investigar os desaparecidos políticos. Em 2000, com o objetivo de ampliar as investigações, foi criada outra comissão, denominada Comisión para la Paz.

${ }^{14}$ STAMPA, Inez; RODRIGUES, Vicente. Os arquivos da ditadura e a Comissão Nacional da Verdade. Revista Perspectiva Histórica, v.2, n.2, janeiro-junho de 2012, p. 23.

${ }^{15}$ STAMPA; RODRIGUES. Os arquivos da ditadura..., p. 23. 
os indultos e leis que impediam a responsabilização penal de civis e militares vinculados à ditadura instaurada em $1976 .{ }^{16}$

No Brasil, a comissão da verdade foi criada pela Lei n. 12.528, de 13 de novembro de 2011, e instituída em maio de 2012, no governo da presidenta Dilma Rousseff, tendo concluído seu relatório final em dezembro de 2014. Mas, como afirma Bauer,

A criação da Comissão Nacional da Verdade não foi a primeira disposição do Estado brasileiro para o esclarecimento das circunstâncias das mortes e dos desaparecimentos ocorridos durante a ditadura civil-militar. A primeira iniciativa oficial tardou quase uma década após o término do regime ditatorial, e se concretizou com a promulgação da Lei n. 9.140, de 5 de dezembro de 1995 e a criação da Comissão Especial sobre Mortos e Desaparecidos Políticos. Posteriormente, complementaram-se as políticas de memória e reparação em curso com o estabelecimento da Comissão de Anistia em 2002. Saliente-se que, desde o período da transição política, ex-presos e perseguidos políticos e familiares de mortos e desaparecidos, juntamente a organizações da sociedade civil e militantes de direitos humanos, realizaram investigações paralelas, que resultaram em dossiês, como "Dossiê dos mortos e desaparecidos políticos desde 1964", com edições publicadas em 1984, 1996 e 2008, e em relatórios como o "Brasil: Nunca Mais", lançado em 1985. ${ }^{17}$

A Comissão Nacional da Verdade (CNV), apesar de uma série de limitações, foi uma contribuição importante para o processo de Justiça de Transição no Brasil, pois tomou depoimentos de vítimas da ditadura militar e dos agentes do Estado que perpetraram violações dos direitos humanos; acumulou um acervo documental importante e construiu, no relatório final, uma narrativa sobre estas referidas violações. Também fez uma série de recomendações visando ao fim da impunidade, contribuindo para a construção de uma memória que visa a uma condenação de regimes ditatoriais. Mas, mesmo assim, a impunidade, principalmente de agentes do Estado que praticaram ou autorizaram torturas de presos políticos e participaram de mortes e desaparecimentos, não se concretizou, inclusive, entre outras coisas, pelo entendimento consolidado no Supremo Tribunal Federal (STM) sobre a Lei da Anistia, de 1979. No contexto de criação e atuação da CNV, também foram criadas por todo país, comissões estaduais, municipais e de entidades da sociedade civil, que atuaram no mesmo sentido, dando visibilidade e construindo memórias sobre a atuação pessoas não contempladas na Comissão Nacional.

Enfim, as comissões da verdade, apesar de suas limitações, tiveram uma função importante, principalmente por serem iniciativas de Estados democráticos, que procuraram "educar para o nunca mais". Mas este papel deve ser desempenhado por vários segmentos da sociedade comprometidos com a democracia e os direitos humanos, e nela os historiadores acadêmicos têm um papel importante a desempenhar.

$\mathrm{Na}$ batalha pelas memórias, a busca de verdade e o dever de memória respondem tanto ao interesse das famílias em saber em quais condições ocorreram as mortes e desaparecimentos forçados, exigindo que sejam punidos os responsáveis por tais atos, quanto ao interesse público em fortalecer a democracia, evitando que o mal se repita. A criação de lugares de memória dedicados ao horror tem a função ética de buscar evitar a repetição de tais crimes.

A partir dos anos de 1980 e, sobretudo, de 1990 em diante, houve uma larga produção da História pública nesses países, através do lançamento de autobiografias de ex-militantes políticos, documentários, filmes, minisséries, entrevistas com vítimas e familiares das vítimas. O uso da História Oral, como metodologia capaz dar voz às vítimas, trouxe a público a dimensão do sofrimento vivido. A partir de então, o testemunho adquiriu um papel fundamental no espaço público, se tornando central na compreensão da dimensão do horror. ${ }^{18}$

No caso argentino, o horror ainda envolveu o sequestro de bebês de militantes políticos entregues a outras famílias. Um drama que ainda persiste com a busca incessante das famílias pela localização

\footnotetext{
${ }^{16}$ BAUER, Caroline Silveira. Como será o passado?: História, historiadores e a Comissão Nacional da Verdade. Jundiaí-SP: Paco, 2017, p. 32-33.

${ }^{17}$ BAUER, Caroline Silveira. Como será o passado?..., p. 32.

${ }^{18}$ JELÍN, Elizabeth. Los trabajos de la memoria. Madrid: Século XXI, Espanha Editores, 2002.
} 
desses bebês, hoje já adultos. Há traumas que serão insuperáveis, sobretudo, para aqueles que foram diretamente atingidos pelo aparato repressivo.

Desejamos que a democracia prevaleça, que o Estado de Direito garanta a liberdade de opinião, de pesquisa e que a promoção da justiça contra qualquer abuso e violação de direitos humanos seja entendida como valor inegociável nos países do Cone Sul. A História é o conhecimento que propõe contribuir para que os valores modernos sejam plenamente realizados, sempre reassumindo seu compromisso ético com o conhecimento como base para a promoção da igualdade social e da vida coletiva. 